Virginia Commonwealth University

vCU Scholars Compass

\title{
Deciphering of interactions between platinated DNA and HMGB1 by hydrogen/deuterium exchange mass spectrometry
}

Yuanyuan Wang

Beijing National Laboratory for Molecular Sciences, University of Chinese Academy of Sciences

Zhifeng Du

Beijing National Laboratory for Molecular Sciences, Virginia Commonwealth University, zdu@vcu.edu

WeiZheng

Beijing National Laboratory for Molecular Sciences

See next page for additional authors

Follow this and additional works at: http://scholarscompass.vcu.edu/chem_pubs

Part of the Chemistry Commons

This journal is (C) The Royal Society of Chemistry 2017

\section{Downloaded from}

http://scholarscompass.vcu.edu/chem_pubs/81

This Article is brought to you for free and open access by the Dept. of Chemistry at VCU Scholars Compass. It has been accepted for inclusion in Chemistry Publications by an authorized administrator of VCU Scholars Compass. For more information, please contact libcompass@vcu.edu. 


\section{Authors}

Yuanyuan Wang, Zhifeng Du, Wei Zheng, Kui Wu, Decheng Xu, Qun Luo, Yao Zhao, Juanjuan Han, Yangzhong Liu, and Fuyi Wang 


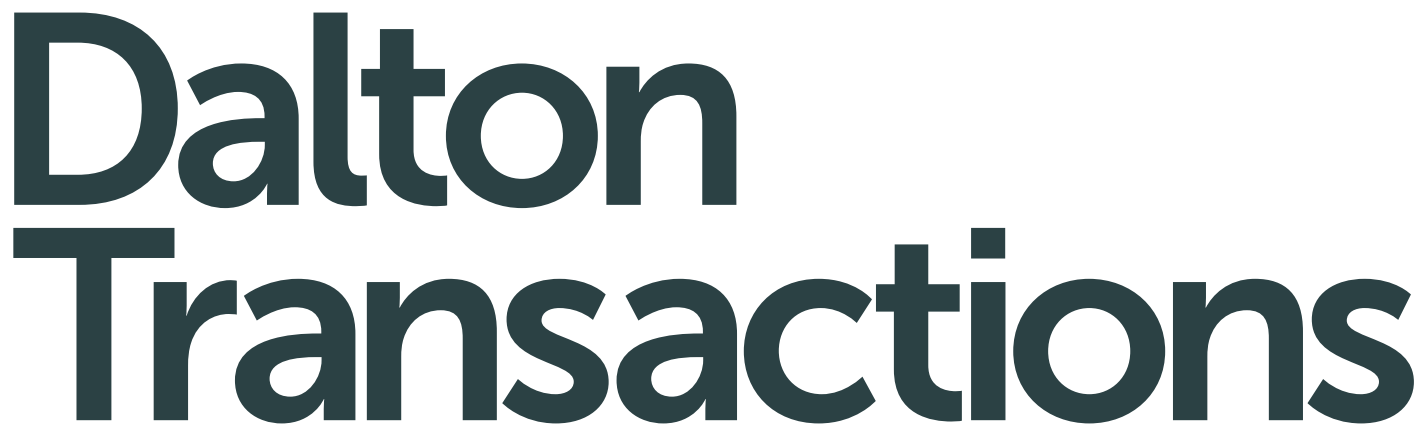

An international journal of inorganic chemistry rsc.li/dalton

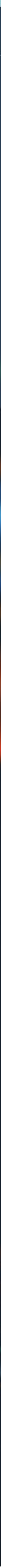

ISSN $1477-9226$

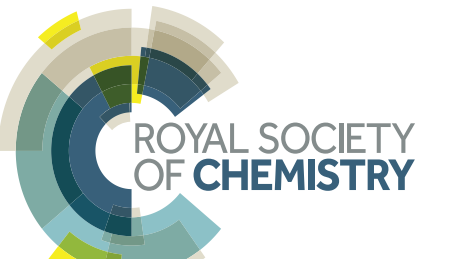

\section{PAPER}

Zhifeng Du, Fuyi Wang et al.

Deciphering of interactions between platinated DNA and HMGB1 by hydrogen/deuterium exchange mass spectrometry 
D) Check for updates

Cite this: Dalton Trans., 2017, 46, 6187

Received 23rd January 2017, Accepted 3rd April 2017

DOI: $10.1039 / \mathrm{c} 7 \mathrm{dt} 00275 \mathrm{k}$

rsc.li/dalton

\section{Deciphering of interactions between platinated DNA and HMGB1 by hydrogen/deuterium exchange mass spectrometry $\dagger$}

\author{
Yuanyuan Wang, ${ }^{a, b}$ Zhifeng Du, ${ }^{\text {a,d }}$ Wei Zheng, ${ }^{a}$ Kui Wu, (D) a Decheng Xu, ${ }^{c}$ Qun Luo, ${ }^{a}$ \\ Yao Zhao, ${ }^{a}$ Juanjuan Han, ${ }^{a}$ Yangzhong Liu (D) ${ }^{c}$ and Fuyi Wang (D) *a,b
}

\begin{abstract}
A high mobility group box 1 (HMGB1) protein has been reported to recognize both 1,2-intrastrand crosslinked DNA by cisplatin (1,2-cis-Pt-DNA) and monofunctional platinated DNA using trans- $\left[\mathrm{PtCl}_{2}\left(\mathrm{NH}_{3}\right)\right.$ (thiazole)] (1-trans-PtTz-DNA). However, the molecular basis of recognition between the trans-PtTz-DNA and HMGB1 remains unclear. In the present work, we described a hydrogen/deuterium exchange mass spectrometry (HDX-MS) method in combination with docking simulation to decipher the interactions of platinated DNA with domain A of HMGB1. The global deuterium uptake results indicated that 1-transPtTz-DNA bound to HMGB1a slightly tighter than the 1,2-cis-Pt-DNA. The local deuterium uptake at the peptide level revealed that the helices I and II, and loop 1 of HMGB1a were involved in the interactions with both platinated DNA adducts. However, docking simulation disclosed different $\mathrm{H}$-bonding networks and distinct DNA-backbone orientations in the two Pt-DNA-HMGB1a complexes. Moreover, the Phe37 residue of HMGB1a was shown to play a key role in the recognition between HMGB1a and the platinated DNAs. In the cis-Pt-DNA-HMGB1a complex, the phenyl ring of Phe37 intercalates into a hydrophobic notch created by the two platinated guanines, while in the trans-PtTz-DNA-HMGB1a complex the phenyl ring appears to intercalate into a hydrophobic crevice formed by the platinated guanine and the opposite adenine in the complementary strand, forming a penta-layer $\pi-\pi$ stacking associated with the adjacent thymine and the thiazole ligand. This work demonstrates that HDX-MS associated with docking simulation is a powerful tool to elucidate the interactions between platinated DNAs and proteins.
\end{abstract}

\section{Introduction}

cis-Diamminedichloroplatinum(II) (cisplatin) is one of the widely used anticancer drugs in the clinic, and has been thought to act by damaging DNA through forming intrastrand $(\mathrm{d}(\mathrm{GpG})$ and $\mathrm{d}(\mathrm{ApG}))$ crosslinks. ${ }^{1}$ While its stereoisomer transdiamminedichloroplatinum(II) (transplatin) is clinically inactive and these two platinum complexes were considered to be a classical paradigm of the structure-activity relationships. However, analogues of transplatin in a general structure of

\footnotetext{
${ }^{a}$ Beijing National Laboratory for Molecular Sciences, National Centre for Mass Spectrometry in Beijing, CAS Key Laboratory of Analytical Chemistry for Living Biosystems, Institute of Chemistry, Chinese Academy of Sciences, Beijing 100190, PR China. E-mail: fuyi.wang@iccas.ac.cn

${ }^{b}$ University of Chinese Academy of Sciences, Beijing 100049, PR China

${ }^{c}$ Department of Chemistry, University of Science and Technology of China, Hefei Anhui, 230026, PR China

${ }^{d}$ Department of Chemistry, Virginia Commonwealth University Richmond, Virginia, 23284-2006, USA. E-mail: zdu@vcu.edu

$\dagger$ Electronic supplementary information (ESI) available: The supplementary Table S1 and Fig. S1-S9. See DOI: 10.1039/c7dt00275k
}

trans-[ $\left[\mathrm{PtCl}_{2}\left(\mathrm{NH}_{3}\right)(\mathrm{L})\right]$, where $\mathrm{L}$ is a planar amine ligand, have been demonstrated to be cytostatic and active even against cisplatin-resistant tumor cells. ${ }^{2}$ A well-known example of such complexes is trans-[ $\mathrm{PtCl}_{2}\left(\mathrm{NH}_{3}\right)$ (thiazole)] (trans-PtTz) (Fig. 1), of

$$
\stackrel{\mathrm{H}_{3} \mathrm{~N}}{\mathrm{H}_{3} \mathrm{~N}}>\mathrm{Pt}<\underset{\mathrm{Cl}}{\mathrm{Cl}}
$$

cisplatin<smiles></smiles>

trans-PtTz

$$
\begin{array}{ll}
\text { 5'-CCTCTCTGGACCTTCC-3' }^{\prime} & \mathbf{I} \\
\text { 3'-GGAGAGACCTGGAAGG-5' }^{\prime} & \text { II } \\
\mathbf{I}+\mathbf{I I}=\mathbf{I I I} & \\
\text { 5'-CCTCTTGTCTCC-3' }^{\prime} & \mathbf{I v} \\
\text { 3'-GGAGAACAGAGG-5' }^{\prime} & \mathbf{v} \\
\mathbf{I v}+\mathbf{v}=\mathbf{v I} &
\end{array}
$$

Fig. 1 Chemical structures of platinum anticancer complexes cisplatin and trans- $\left[\mathrm{PtCl}_{2}\left(\mathrm{NH}_{3}\right)\right.$ (thiazole)] (trans-PtTz), and the sequences of DNA segments used in this work. The guanines in bold in strands I and IV indicate the binding sites for cisplatin and trans-PtTz, respectively. 
which the unique anticancer activity has also been attributed to DNA damage by forming diverse covalent platinated adducts, including 1,3-intrastrand, 1,2-interstrand crosslinks, and monofunctional DNA adducts. ${ }^{3}$

A high mobility group box 1 protein (HMGB1) containing domains A and B followed by a long acidic tail was one of the most important nuclear proteins participating in regulating numerous nuclear processes. ${ }^{4} \mathrm{~A}$ large number of research studies have shown that HMGB1 can specifically recognize cisplatinated DNA containing a 1,2-GG intrastrand crosslink which accounts for $\sim 65 \%$ of the total cisplatin crosslinked DNA. ${ }^{5}$ X-ray crystallography in combination with mutagenesis and hydroxyl-radical foot printing has been applied to elucidate the structure of the 1,2-cisplatinated-DNA-HMG-domain complex, in which the domain A of HMGB1 from rats binds to a 16 bp double-stranded DNA (dsDNA) containing a single intrastrand crosslink cis- $\left[\mathrm{Pt}\left(\mathrm{NH}_{3}\right)_{2}\left\{\mathrm{~d}(\mathrm{GpG})-\mathrm{N} 7\left(\mathrm{G}_{8}\right), \mathrm{N} 7\left(\mathrm{G}_{9}\right)\right\}\right] .{ }^{6} \mathrm{~A}$ key binding site found in the cisplatinated-DNA-HMGB1a complex is the Phe37 residue, which intercalates into a hydrophobic notch formed at the opposite side of the platinum crosslinked $\mathrm{d}(\mathrm{GpG})$ site. Such binding was dramatically reduced when Phe37 was mutated to alanine. ${ }^{6}$ Moreover, other noncovalent interactions such as van der Waals contacts which involve V35, R23, V19, and A16 of HMGB1a, and hydrogen bonding or salt bridging between HMGB1a, including K11, S14, Y15, Q20, R23, S41, K42, S45, W48 and K56 residues, and the cisplatinated DNA were also observed. ${ }^{6}$

For trans-PtTz, three types of DNA adducts are formed nearly in equal amounts and it is believed that the cytotoxicity of trans-PtTz was the sum of all three types of DNA damages which trigger distinct cellular responses and result in cytotoxicity. ${ }^{7}$ For instance, the monofunctional trans-PtTz-DNA adduct could also be recognized by HMGB1, ${ }^{3 a}$ and we have recently demonstrated by mass spectrometric proteomic studies that the human nuclear protein positive cofactor PC4 specifically binds to $1,3-\mathrm{GNG}$ crosslinked DNA by trans-PtTz. ${ }^{8}$ However, the detailed molecular basis for the recognition between these proteins and different trans-PtTz-dsDNA adducts remains largely unclear.

A hypothesis proposes that the monofunctional DNA adducts by trans-PtTz may create a local conformational distortion similar to that in the 1,2-GG crosslinked DNA by cisplatin, and the planar thiazole ligand might intercalate into the duplex and stack with aromatic rings of bases. As a consequence, the targeted DNA duplex would unwind and bend, similar to that resulting from the 1,2-GG cisplatinated crosslinking. ${ }^{9}$ Although the monofunctional trans-PtTz-DNA has been shown to be recognized by HMGB1, ${ }^{3 a}$ little information has been gained to elucidate the molecular basis of this recognition. Therefore, in the present work we have developed a hydrogen/deuterium exchange mass spectrometry (HDX-MS) method to investigate the interactions, particularly binding the epitope of HMGB1a to mono-platinated DNA by trans-PtTz.

HDX-MS elucidates the conformation and dynamics of proteins, protein-protein and protein-ligand interactions, and localizes the binding regions (or sites), in particular noncova- lent binding sites of ligands to proteins. ${ }^{10}$ Of the many different kinds of hydrogen atoms in proteins, only the hydrogens located at the peptide backbone amide linkages (NHs) have exchange rates with deuterium in solution within a range that can be easily measured by MS. The backbone amide hydrogens involved in the formation of weak hydrogen bonds or located at the surface of the protein can exchange rapidly, whereas those buried in the interior or those involved in strong hydrogen bonds exchange more slowly. By measuring HDX rates of backbone amides after being quenched at low $\mathrm{pH}$ and low temperature one can obtain structural information on protein dynamics and conformation. In the cases of probing protein-ligand interactions using HDX-MS, the difference in global deuterium uptake between the native proteins and the ligated proteins can be indicative of the interactions between the proteins and the ligands as some solventaccessible amides located within the interaction regions are shielded from deuterium exchange, retarding the global deuterium uptake of the proteins. ${ }^{11}$ Furthermore, spatial resolution in the range of 1-10 residues can be obtained by coupling mass spectrometry with proteolytic digestion by pepsin under the HDX quenching conditions following separation of high performance liquid chromatography (HPLC). The kinetic analysis of deuterium uptake of an individual peptide and/or the local deuterium uptake will then reveal the binding sites (or regions) of the protein-ligand complex. ${ }^{10 b, 12}$

\section{Results and discussion}

\section{Global hydrogen/deuterium exchange}

The HMGB1 protein consists of two domains (domain A termed as HMGB1a and domain B as HMGB1b) and an acidic C-terminal with a short lysine-rich A-B linker and a 23-aminoacid B-C linker. ${ }^{13}$ Reports have shown that full-length HMGB1 as well as HMGB1a/HMGB1b can all specifically bind to the 1,2-GG or AG intrastrand crosslinked DNA by cisplatin ${ }^{14}$ and HMGB1a is the core to dominate such specific binding. ${ }^{15}$ HMGB1a also showed relatively higher affinity to DNA containing a monofunctional bound trans-PtTz than HMGB1b. ${ }^{3 a}$ Therefore in this work only the HMGB1a domain was chosen for the investigation of interactions with platinated DNA, 1,2cis-Pt-III and 1-trans-PtTz-VI (Fig. 1) of which the details of preparation are given in the Experimental section.

Firstly, the global deuterium uptake of HMGB1a with and without binding to platinated DNA adducts was measured and compared. Global HDX is often the first step of an HDX experiment to find out if a particular ligand has an effect on the secondary and tertiary structure of a protein. ${ }^{16}$ Our first attempt to obtain global HDX data on HMGB1a with an excess of platinated DNA adducts by ESI-MS coupled with reversed-phase liquid chromatography failed due to the lack of protein signals. Following various times of incubation in $90 \% \mathrm{D}_{2} \mathrm{O}$, the deuterated protein is placed in a low pH (e.g. pH 2.5) buffer at low temperature $\left(\approx 2{ }^{\circ} \mathrm{C}\right)$ to quench the H/D exchange during subsequent HPLC separation and electrospray ionisation mass 
spectrometry (ESI-MS) analysis. As low $\mathrm{pH}(\approx 2.5)$ is required for quenching $\mathrm{H} / \mathrm{D}$ exchanges, most of the proteins should be positively charged as all carboxylic groups $\left(\mathrm{p} K_{\mathrm{a}} \approx 4.6\right)$ will be effectively protonated, leaving only basic amino acids positively charged. DNA and RNA, on the other hand, will still have a substantially negative net charge due to the presence of the phosphate backbone. Hence, the low $\mathrm{pH}$ may result in the formation of stable protein/nucleic acid precipitates which in turn interfere with the HPLC separation of protein-DNA complexes and mass spectrometric analysis of the proteins. ${ }^{17}$ Usually, there were two methods to solve this signal suppression problem: applying a strong anion exchange (SAE) column to trap the nucleic acids ${ }^{18}$ or using protamine sulfate to precipitate nucleic acids. ${ }^{17}$ Given that the SAE trap extends the time of HPLC-MS analysis, herein we chose protamine sulfate to precipitate excess of DNA prior to HPLC-MS analysis. As shown in Fig. S1 in the ESI, $\uparrow$ even with 10-fold excess of 1,2cis-Pt-III, the obvious mass spectrum of HMGB1a could be obtained. The deuterium uptake of unligated HMGB1a was measured to be $(27.7 \pm 1.0)$ and $(27.4 \pm 1.2)$ in the absence and in the presence of protamine sulfate (data not shown here), which means that there is no effect of protamine sulfate on the HDX reactions of HMGB1a.

The apo-HMGB1a (unligated) approached the maximum numbers of deuterium after ca. $5 \mathrm{~min}$ of $\mathrm{HDX}$ at $295 \mathrm{~K}$ (Fig. 2a), suggesting the fast-exchanging of backbone amido hydrogens of HMGB1a without any ligands. The maximum mass shift of $40 \mathrm{Da}$ is less than the number of amido hydrogens available for deuterium incorporation (72). The ratio of deuteration $(55.6 \%)$ is less than the percentage $(90 \%)$ of $\mathrm{D}_{2} \mathrm{O}$ used in the buffer, most probably attributed to the substantial back exchange of hydrogens from $\mathrm{H}_{2} \mathrm{O}$ and/or the local hiding of amido hydrogens from the solvent. For HMGB1a, such a low deuterium exchanging rate was mainly attributed to the three stable $\alpha$-helices (Fig. S2, ESI $\dagger$ ).

Due to the binding of the cisplatinated DNA (1,2-cis-Pt-III), the deuterium uptake of the holo-HMGB1a (ligated) at $5 \mathrm{~s}$ significantly decreased to 6.7 , which is $27 \%$ less than that of apo-HMGB1a (Fig. 2a). With the elevation in incubation time,
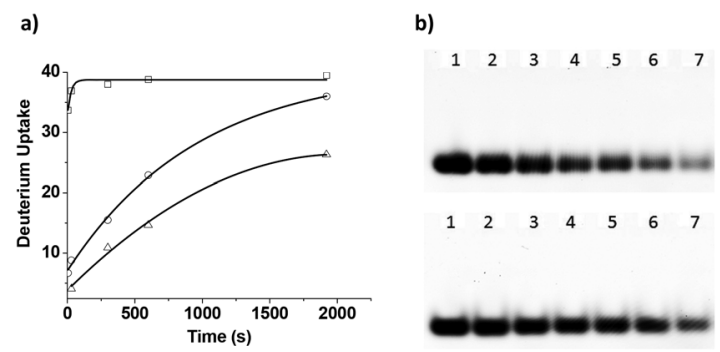

Fig. 2 (a) Kinetic curves for the global deuterium incorporation of nonligated HMGB1a (- - ) and ligated HMGB1a with 1,2-cis-Pt-III (-O-) or 1-trans-PtTz-VI $(-\Delta-)$. (b) EMSAs for $0.1 \mu \mathrm{M}$ of 1,2-cis-Pt-III (top panel) and 1-trans-PtTz-VI (bottom panel) in the presence of HMGB1a. The concentrations of HMGB1a for lane 1-7 were $0,0.1,0.2,0.4,0.6,0.8$ and $1 \mu \mathrm{M}$, respectively. the exchanging deuterium number of holo-HMGB1a gradually increased and reached 36 at $32 \mathrm{~min}$, but still a little lower than the incorporated deuterium (39.5) of apo-HMGB1a with the same incubation time. These indicate that the conjugation of the cisplatin-intrastrand crosslink to HMGB1a significantly shielded the backbone amido hydrogens of the protein from exchanging with deuterium in solution.

Similar situation has been observed for the HDX of HMGB1a ligated with the monofunctional DNA (1-transPtTz-VI) under the same conditions (Fig. 2a). Moreover, HMGB1a bound to 1-trans-PtTz-VI showed much less deuterium incorporation (26.3) than those of apo-HMGB1a (39.5) and holo-HMGB1a (36) with 1,2-cis-Pt-III at $32 \mathrm{~min}$. The HDX rate as pseudo-first order reactions of the apo-HMGB1a, and HMGB1a ligated with 1,2-cis-Pt-III and 1-trans-PtTz-VI are calculated to be $(4.0 \pm 0.8) \times 10^{-2},(1.0 \pm 0.1) \times 10^{-3}$, and $(9.1 \pm 1.3) \times 10^{-4} \mathrm{~s}^{-1}$, respectively, based on the kinetic curves of HMGB1a in different states (Fig. 2a). These indicate that the binding affinity of the monofunctional DNA by trans-PtTz to HMGB1a is similar to that of the cisplatin crosslinked DNA to the protein, consistent with the previous report. ${ }^{3 a}$ Such similarity between the HDX reactions of HMGB1a bound to the two platinated DNA also suggests that the mono-functional binding of trans-PtTz to DNA causes similar distortion of DNA structure to that induced by bifunctional binding of cisplatin.

Electrophoretic mobility shift assays (EMSAs) were performed to provide an additional quantitative view of the binding affinity of HMGB1a towards different damaged DNA segments. Fluorescein-labeled 1,2-cis-Pt-III and 1-trans-PtTz-VI were prepared as described in the Experimental section. The EMSA results are displayed in Fig. 2b. In each gel, lane 1 contains $0.1 \mu \mathrm{M}$ of 1,2-cis-Pt-III or 1-trans-PtTz-VI in the absence of HMGB1a, lanes 2-7 correspond to the Pt-DNA-HMGB1a complexes generated in the presence of various concentrations of the protein. As shown in Fig. 2b, the shift of both of the platinated DNA segments were significantly retarded due to the presence of HMGB1a, indicating the formation of PtDNA-HMGB1a complexes. However, there were no hysteretic bonds observed in all lanes even in the presence of 10 -fold excess of HMGB1a. This may be attributed to the charge neutralization of the negatively charged DNA segments by HMGB1a (pI: 9.58 ${ }^{19}$ ) under the given $\mathrm{pH}$ (8.1). According to the EMSA data, there is no pronounced difference in the binding affinity of HMGB1 to the two platinated DNA segments. This suggests that HDX-MS is more sensitive for probing the binding affinity of platinated DNA to proteins.

\section{Local hydrogen/deuterium exchange}

Local deuterium uptake studies can expand the resolution of mapping the binding sites of protein-ligand complexes to a short peptide level. To decipher the binding epitope of platinated DNA to HMGB1a, a peptide mass fingerprint (PMF) of apo-HMGB1a was firstly generated by HPLC-ESI-MS analysis following the pepsin digestion of the protein. Six peptides labeled as T1-T6 with only Met62 missed were identified (Table 1) with sufficient signal-to-noise ratios. Exact masses of 
Table 1 Peptides identified by HPLC-ESI-MS analysis of peptic digest of HMGB1a

\begin{tabular}{|c|c|c|c|c|c|}
\hline Peptide & Sequence \& position ${ }^{a}$ & Observed $\mathrm{m} / \mathrm{z}$ & Theoretical $\mathrm{m} / \mathrm{z}$ & $\delta(\mathrm{ppm})$ & Method \\
\hline $\mathrm{T} 2$ & $\mathrm{~S}_{14} \mathrm{YAFFVQTCREEHKKKHP}_{31}$ & $559.5345^{4+}$ & $559.5336^{4+}$ & 1.61 & Exact mass \\
\hline T5 & $\mathrm{S}_{41} \mathrm{KKCSERWKT}_{50}$ & $626.8304^{2+}$ & $626.8281^{2+}$ & 3.67 & Exact mass \\
\hline T6 & $\mathrm{A}_{63} \mathrm{KADKARYEREMKTY}_{77}$ & $930.4656^{2+}$ & $930.4766^{2+}$ & 11.82 & Exact mass \\
\hline
\end{tabular}

${ }^{a}$ The sequence and the secondary structural elements of HMGB1a is shown in Fig. S2. The sequence position follows the X-ray crystal structure reported previously (PDB code: $1 \mathrm{CKT}){ }^{6}$

these peptides were determined through adding internal standards, substance $\mathrm{P}(\mathrm{m} / \mathrm{z} 674.8672, z=2+)$ to the digested sample. The experimentally measured peptide masses were matched with the calculated masses of peptides using the FindPept software ${ }^{20}$ within a 20 ppm error. In cases where mass matching gave more than one hit within a $20 \mathrm{ppm}$ window, peptide sequences were identified by MS/MS analysis. As HMGB1a is hydrophilic, a high sequence coverage of $99 \%$ was achieved (Fig. S2, ESI $\dagger$ ), providing adequate structural information for localizing the interaction regions between HMGB1a and platinated DNA fragments.

Next we measured the deuterium uptake of an individual peptic peptide of apo-HMGB1a and holo-HMGB1a ligated with platinated DNAs. The typical ESI mass spectra of peptides T1 (S5-F17), T2 (S14-P31), T3 (Q20-D61), T4 (H26-C44) and T5 (S41-T50), derived from apo- and holo-HMGB1a ligated with 1,2-cis-Pt-III subjected to 1 min continuous HDX at $295 \mathrm{~K}$, are shown in Fig. 3a, b and S3. $\dagger$ The kinetic plots over a $10 \mathrm{~min}$ time course for the five peptides are shown in Fig. S4. $\dagger$ The peptic peptide T6 (A63-Y77) showed no change in deuterium uptake between apo- and holo-HMGB1a (data not shown). Amido hydrogens involved in $\alpha$-helix will exchange more slowly than those that are unstructured and not involved in hydrogen bonding. The peptides T1-T5, which have some sequence overlap through the three helices, all displayed a pronounced decrease in deuterium uptake upon the complexation of HMGB1a with 1,2-cis-Pt-III, indicating that all these regions were involved in the recognition with the damaged DNA. After 1 min deuteration, the deuteration ratios of T1-T5 derived from the 1,2-cis-Pt-III-HMGB1a complex were 36.5\%, 33.3\%, $15.7 \%, 28.8 \%$ and $11.0 \%$, respectively, significantly lower than those of T1-T5 $(53.5 \%, 65.2 \%, 33.0 \%, 54.3 \%$ and $46.4 \%$, respectively) derived from apo-HMGB1a (Table S1 and Fig. 3c, S4, ESI $\dagger$ ). This means that about 1.7, 4.6, 6.2, 4.4 and 2.5 amido hydrogens, respectively, in T1-T5 were excluded from exchanging with $\mathrm{D}_{2} \mathrm{O}$ due to the binding of the cisplatinated DNA to HMGB1a. After $10 \mathrm{~min}$ HDX, the deuteration ratios of T1-T5 from the holo-HMGB1a increased to 55\%, $70.8 \%$, $42.9 \%, 55.9 \%$ and $45.8 \%$, respectively (Table S1 and Fig. S4, ESI $\dagger$ ). In particular, the deuteration ratios of $\mathrm{T} 2$ and $\mathrm{T} 3$ were nearly the same as those of $\mathrm{T} 1$ and $\mathrm{T} 2$ derived from apoHMGB1a. Accompanied by these, the excluded amido hydrogen number was decreased to $1.2,0.6,1.0,1.3$ and 1.1 , respect-
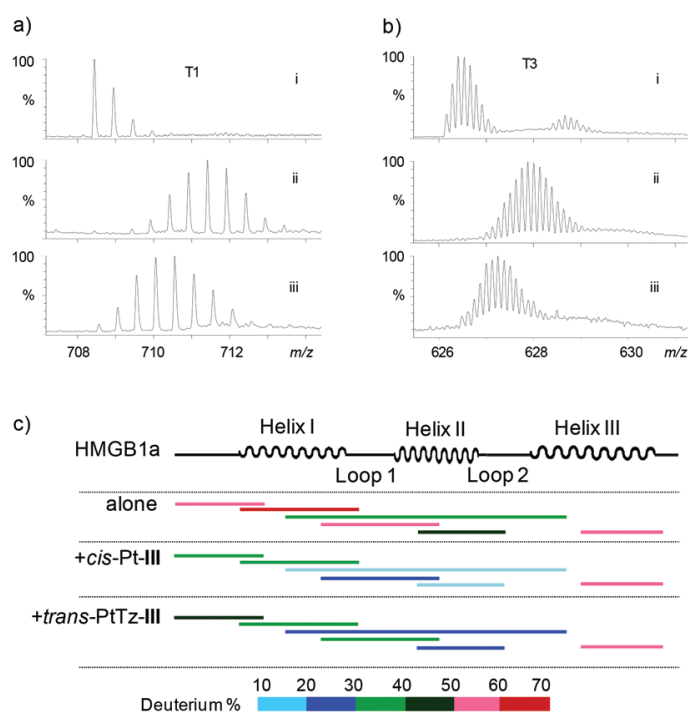

Fig. 3 (a, b) Mass spectra of peptic peptides T1 (S5-F17) and T3 (Q20D61). (i) Non-deuterated peptides; (ii) deuterated peptides of nonligated HMGB1a and (iii) deuterated peptides of ligated HMGB1a with 1,2-cis-Pt-III after incubated in $\mathrm{D}_{2} \mathrm{O}$ buffer for $1 \mathrm{~min}$. (c) Deuterium incorporation (\%) of peptic peptide of HMGB1a with and without platinated DNA, showing a slowed HDX rate upon platinated DNA binding except for the $\mathrm{C}$-terminal region after being incubated in $\mathrm{D}_{2} \mathrm{O}$ buffer for $1 \mathrm{~min}$.

ively, for T1-T5 in the holo-HMGB1a. The deuteration rates of T1 (S5-F17) and T5 (S41-T50) in holo-HMGB1a were slower than those of the other three peptides, indicating stronger interactions of these regions with cisplatinated DNA.

In the crystal structure of the 1,2-cis-Pt-III-HMGB1a complex, ${ }^{6}$ all the three helices are involved in the interaction with the cisplatinated DNA through different ways. The helix I mainly interacts with the sugar-phosphate backbone at the unmodified part of the DNA duplex, helix II mainly interacts with the backbone of the platinated part, while helix III has weaker interactions with only one water-mediated contact with the platinated DNA duplex. This explains the lack of HDX variations of T6 between apo- and holo-HMGB1a with 1,2-cis-Pt-III observed here.

Utilizing the same HDX-MS method described above, we studied the deuteration of holo-HMGB1a ligated with 1-trans- 
PtTz-VI. After 1 min HDX, the deuteration ratios (\%) of T1-T5 in the holo-HMGB1a were measured to be 46.4, 32.7, 24.1, 33.7 and 28.1, respectively (Table S1 and Fig. 3c, S5, ESI $\dagger$ ). Compared to those of the respective peptides (59.2, 65.7, 34.9, 60.5 and 41.9, respectively, Table S1 $\dagger$ ) in the apo-HMGB1a, we calculated that about 1.3, 4.8, 3.9, 4.1 and 1.0 amido hydrogens, respectively, in T1-T5 were excluded from exchanging with $\mathrm{D}_{2} \mathrm{O}$ due to binding to 1-trans-PtTz-VI.

Except for T3, the deuteration ratios of the other four peptides in the holo-HMGB1a are still significantly lower than those of the respective peptides from apo-HMGB1a after 10 min of deuteration (Fig. S5, ESI $\dagger$ ). In particular, the deuterium incorporation of T2 (S14-P31) in the holo-HMGB1a was ca. $20.3 \%$ less than that of T2 in the apo-HMGB1a. These results imply a closer contact of 1-trans-PtTz-VI with HMGB1a than 1,2-cis-Pt-III in the region of $\mathrm{S} 14$ to $\mathrm{P} 31$ residues. Based on the HDX rates at the peptide level, the 1-trans-PtTz-VI adduct binds to HMGB1a on the region involving peptides $\mathrm{T} 2$, $\mathrm{T} 4$ and T5, of which the sequence covers residues through S14 to F50 and spans helix I, loop 1 and helix II. This is similar to the binding region of the 1,2-cis-Pt-VI adduct to HMGB1a as revealed by our HDX-MS analysis (vide supra) and X-ray crystallographic characterization reported previously. ${ }^{3 a, 21}$ However, as the detailed conformation of 1-trans-PtTz-VI binding to HMGB1a may be different from that of 1, 2-cis-Pt-III-HMGB1a binding to HMGB1a (vide infra), the changes in the HDX rate of individual peptic peptide derived from HMGB1a induced by the binding of 1-trans-PtTz-VI were slightly different from those induced by the binding of 1, 2-cis-Pt-III (Table S1, ESI $\dagger$ ).

It is notable that under the given conditions, the peptic peptides of HMGB1a were generally long (Table 1), which does not allow exact identification of the binding sites at the amino acid resolution of 1-trans-PtTz-VI to HMGB1. To achieve this goal, molecular docking simulations were next performed.

\section{Docking simulations}

The X-ray crystal structure of 1,2-cis-Pt-III-HMGB1a complex (PDB code: $1 \mathrm{CKT})^{6}$ was used to develop and validate the docking simulation strategy. The 3D molecular models of HMGB1a and 1,2-cis-Pt-III were re-constructed by extracting the respective molecule from the crystal structure following energy-minimization. Then, the 1,2-cis-Pt-III molecule was docked back into the HMGB1a receptor following the procedure described in the Experimental section. The resulting molecular model (Fig. 4a and c) shows that the region of HMGB1a spanning helix I, loop 1 and helix II is involved in the binding to 1,2-cis-Pt-III, and that both the helices lie on the minor groove next to the major groove housing the platinated site of the cisplatinated duplex (Fig. 4a and c). The conformation of the 1,2-cisplatin crosslinked duplex binding to HMGB1a in the molecular model superimposes well onto that of the platinated crosslink binding to HMGB1a in the crystal structure (Fig. S6, ESI $\dagger$ ). As shown in the enlarged view of the molecular model (Fig. 4a), the Phe37 residue intercalates into the hydrophobic cleft created by the two platinated guanines (G7 and G8), also consistent with the X-ray crystallographic
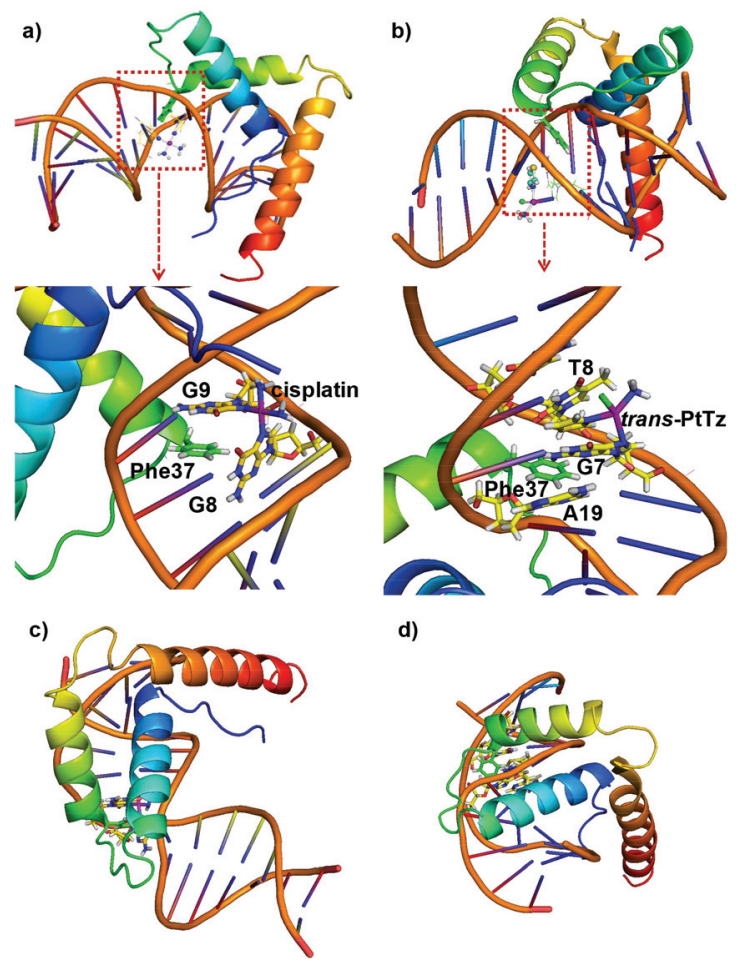

d)

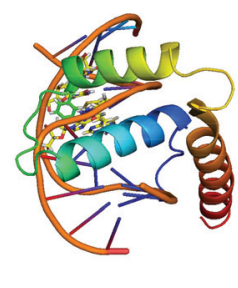

Fig. 4 The conformers/poses in different views of $(a, c)$ 1,2-cis-Pt-III and (b, d) 1-trans-PtTz-VI interacting with HMGB1a generated by docking simulation. The enlarged views in a and b depict the intercalation of the Phe37 residue between bases G8 and G9 in the 1,2-cis-Pt-IIIHMGB1 complex and between G7 and A19 in the 1-trans-PtTz-VIHMGB1a complex, respectively.

results previously reported. ${ }^{6}$ Moreover, a similar hydrogen bonding network, which mainly involves Ser41, Lys42, Ser45 and Trp48 residues of HMGB1a, was observed between the molecular model and the crystal structure of the 1,2-cis-Pt-IIIHMGB1a complex (Fig. 4a and S7, ESI†). These suggest that the docking simulation method used herein is applicable, so the monofunctional platinated duplex 1-trans-PtTz-VI was docked into HMGB1a following the same procedure described above. Surprisingly, the resulting molecular model demonstrates that 1-trans-PtTz-VI binds to HMGB1a with a totally different orientation from that of 1,2-cis-Pt-III to the protein (Fig. 4b and d), though both of them interact with HMGB1a in a similar region. The helices I and II appear to ride between the minor groove and the adjacent major groove containing the platinated site (G7) (Fig. 4b and d). Similar intercalation of the Phe37 residue into the minor groove of the transplatinated duplex was also observed in the model of the 1-trans-PtTz-VIHMGB1a complex, but Phe37 appears to insert into the hydrophobic crevice formed by the platinated G7 and non-modified A19 in the complementary strand (Fig. 4b), leading to the formation of a quintuplicate $\pi-\pi$ stacking involving $\mathrm{T} 8$, triazole ligand, G7, Phe37 and A19. Compared with the 1,2-cis-Pt-IIIHMGB1a complex, more hydrogen bonds are observed in the 1-trans-PtTz-VI-HMGB1a complex, which involve residues Tyr15, Gln20, Arg23, Val35, Asn36, Ser38, Lys42 and Lys58 of 

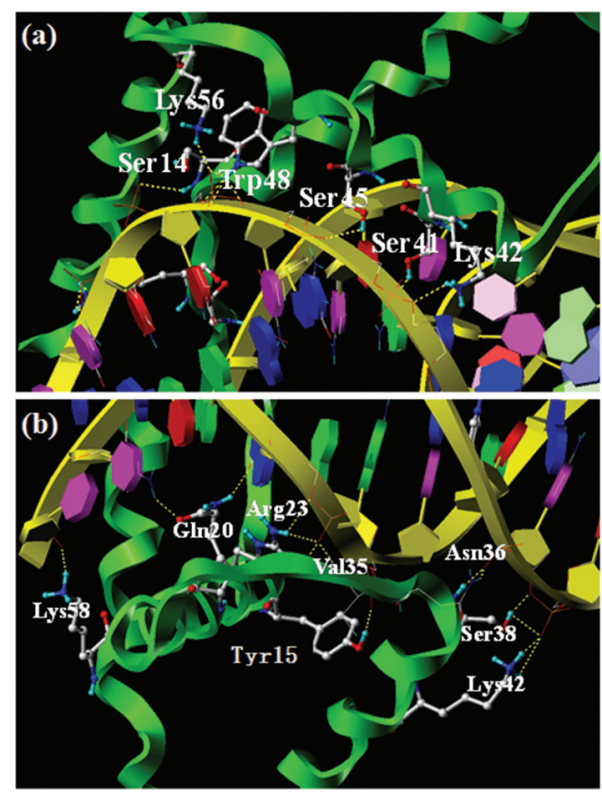

Fig. 5 The conformations of HMGB1a ligated with (a) 1,2-cis-Pt-III and (b) 1-trans-PtTz-VI are generated by docking simulation. The dotted yellow lines illustrate the positions of $\mathrm{H}$-bonding interactions between HMGB1a and the platinated DNAs.

HMGB1a (Fig. 5b). Among these residues, only Lys42 is found to form $\mathrm{H}$-bonds with both the cisplatinated and the transplatinated DNA adducts. This again indicates that the transplatinated duplex takes a different orientation from the cisplatinated duplex to bind to HMGB1a, leading to the formation of more $\mathrm{H}$-bonds than the binding of the cisplatinated duplex to the protein.

Combined the local HDX-MS and the docking simulation results described above, we render the deuterium incorporation map of HMGB1a alone, 1,2-cis-Pt-III-HMGB1a and 1-trans-PtTzVI-HMGB1a complexes to depict the binding regions of 1,2-cis-PtIII and 1-trans-PtTz-VI to HMGB1a in terms of HDX slowing of amido hydrogens in HMGB1a. The results (Fig. 6) indicate that the binding of the transplatinated duplex led to a pronounced

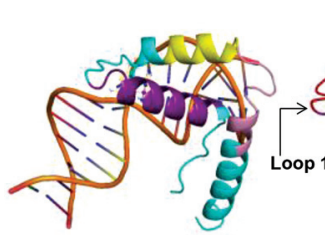

1,2-cis-Pt-III-HMGB1a

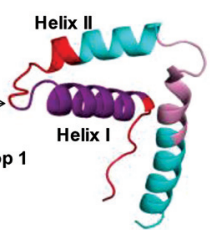

HMGB1a

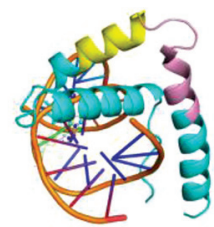

1-trans-PtTZ-VI-HMGB1a $\begin{array}{llllll}40 & 50 & 60 & 70 & 80 & \text { undetermined }\end{array}$

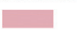

Fig. 6 Deuterium incorporation mapping of HMGB1a in the nonligated form, and in 1,2-cis-Pt-III-HMGB1a and 1-trans-PtTz-VIHMGB1a complexes after being incubated with $90 \% D_{2} \mathrm{O}$ for $10 \mathrm{~min}$. The maps were rendered by Pymol program based on HDX-MS data, and depict the interactive regions in terms of HDX slowing in helix II and loop 1 (1,2-cis-Pt-III-HMGB1a), or in helices I, II and loop 1 (1-transPtTz-VI-HMGB1a).

decrease in deuterium incorporation of the N-terminal, helix I, loop 1 and helix II even after 10 min of HDX, while the binding of the cisplatinated duplex reduced only the HDX rate of loop 1 and helix II. This is in line with the docking simulation results that the binding of 1-trans-PtTz-VI to HMGB1a leads to the formation of a stronger $\pi-\pi$ stacking and more H-bonds between the protein and modified DNA than the binding of 1,2-cis-Pt-III to the protein, implying that 1-trans-PtTz-VI binds to HMGB1a more tightly than 1,2-cis-Pt-III.

\section{Conclusions}

In summary, we have developed a HDX-MS method in combination with molecular docking simulation to investigate the noncovalent interactions between HMGB1a and mono-platinated DNA duplex by trans-PtTz with the binding of the cisplatinated DNA crosslink to the protein as a reference. The global HDX-MS analysis allows evaluating the binding affinity of the protein to the platinated DNA duplexes, and local HDX-MS probing at the peptide level enables mapping the interaction regions (sites) of the protein receptor with the modified DNA ligands. Furthermore, molecular docking simulation provides the conformation and pose in details of the receptor-ligand complexes to verify the experimental results obtained by HDX-MS analysis. The results reveal that HMGB1a binds to the mono-functional modified DNA duplex in a distinct mode from that to the cisplatin-crosslinked DNA duplex, though the modified DNA duplexes bind to HMGB1a in a similar region involving residues through S14 to F50 spanning helix I, loop 1 and helix II of the protein. The Phe37 residue was demonstrated to play a key role in the interaction of HMGB1a with both of the modified DNA segments, inducing the formation of a triple-layer and a penta-layer $\pi-\pi$ stacking in the 1,2 -cis-PtIII-HMGB1a and 1-trans-PtTz-VI-HMGB1a complexes, respectively. Moreover, the binding of 1-trans-PtTz-VI to HMGB1a leads to the formation of more $\mathrm{H}$-bonds than that resulting from the binding of 1,2-cis-Pt-III to the protein. These together make 1-trans-PtTz-VI bind to HMGB1a more tightly than 1,2cis-Pt-III. The present work demonstrates that HDX-MS in combination with molecular docking simulation is a powerful tool to elucidate the noncovalent interactions between proteins and damaged DNA by metallodrugs, and is anticipated to provide insights into better understanding of the molecular basis of recognition between proteins and DNA lesions.

\section{Experimental section}

\section{Materials}

Pepsin was purchased from Sigma-Aldrich and used without further purification. Deuterium oxide (99.8\%) was purchased from Norell Inc. (Landisville, NJ, USA) and protamine sulfate from Sigma. Formic acid (FA) was bought from Acros (Belgium); tetraethylammonium acetate (TEAA, $1 \mathrm{M}$ ) from AppliChem (Germany) and acetonitrile (HPLC grade) from 
Merck (Germany). Complementary single-stranded oligonucleotides (ONTs) I (5'-CCTCTCTGGACCTTCC-3') and II (5'-GGAAGGTCCAGAGAGG-3'), IV (5'-CCTCTTGTCTCC-5') and V (5'-GGAGACAAGAGG-3') were obtained from TaKaRa (Dalian, China). Cisplatin was purchased from Alfa Aesar and trans$\left[\mathrm{PtCl}_{2}\left(\mathrm{NH}_{3}\right)\right.$ (thiazole)] (trans-PtTz) (Fig. 1) was prepared following the procedure reported previously. ${ }^{22}$ Aqueous solutions were prepared using MilliQ water (Milli-Q Reagent Water System).

\section{Expression and purification of HMGB1a}

The cDNAs encoding the HMGB1 domain A were prepared by means of PCR from a human bone marrow cDNA library and cloned into the vector LIC-SG1. The protein was expressed in gold cells. Cells were grown in 1 liter of LB with $1 \mu \mathrm{g} \mathrm{mL}$ ampicillin to an $\mathrm{OD}_{600}$ of 0.6 at $310 \mathrm{~K}$, and induced with $0.8 \mathrm{mM}$ isopropyl $\beta$-D-thiogalactoside. The cells were allowed to grow for 5 hours before harvesting. The cell pellets were thawed in $200 \mathrm{mM} \mathrm{NaCl} / 20 \mathrm{mM}$ Tris buffer ( $\mathrm{pH} \mathrm{8})$ and lysed by sonication. The protein was extracted from the lysates by $\mathrm{Ni}^{2+}$ affinity chromatography (Qiagen). The $\mathrm{Ni}^{2+}$ affinity beads were washed three times with 10 column volumes of buffer containing $200 \mathrm{mM} \mathrm{NaCl}, 50 \mathrm{mM}$ Tris and $30 \mathrm{mM}$ imidazole ( $\mathrm{pH} 8$ ), and the proteins were eluted with 10 column volumes of $250 \mathrm{mM}$ imidazole in the same buffer. The His-tag was removed by cleavage by TEV protease at $16{ }^{\circ} \mathrm{C}$ overnight. The final purification of HMGB1a was performed by FPLC purification on a Hiload Superdex 75 column (GE Health) and protein concentrations were determined by UV-Vis spectroscopy from the absorbance at $280 \mathrm{~nm}$ using $\varepsilon=$ $9970 \mathrm{M}^{-1} \mathrm{~cm}^{-1}$.

\section{Preparation of platinated DNA}

The platinated single-stranded ONT I by cisplatin was prepared as described in the literature. ${ }^{23}$ Briefly, cisplatin was incubated with the -GG- strand at a molar ratio of $\mathrm{Pt} / \mathbf{I}=0.8: 1$ at $310 \mathrm{~K}$ for 3 days. Then the platinated strand was purified by HPLC using a $C_{8}$ column $(4.6 \times 250 \mathrm{~mm}, 5 \mu \mathrm{m}$, Agilent $)$ on an Agilent 1200 HPLC system where the mobile phases were water containing $20 \mathrm{mM}$ TEAA (solvent A) and acetonitrile containing $20 \mathrm{mM}$ TEAA (solvent B). The HPLC fraction containing the cisplatinated strand was collected, lyophilized and then characterized by MALDI-TOF-MS (Fig. S8a, ESI $\dagger$ ). The concentration of the purified cisplatinated strand I was measured by a 2550 UV-VIS spectrometer (Shimadzu, Japan). The cisplatincrosslinked double-stranded ONT III (1,2-cis-Pt-III) was prepared by hybridization of the purified cisplatinated strand I with equiv. molar complementary strand II in $100 \mathrm{mM}$ $\mathrm{NaClO}_{4}$. The formation of double-stranded ONT containing cisplatin lesion sites was confirmed by circular dichroism (CD) spectroscopy and FT-ICR-MS (Fig. S8c and e, ESI†).

The monofunctional platinated single-stranded ONT IV by trans-PtTz, of which the formation was confirmed by ESI-QTOF-MS analysis (Fig. S8b, ESI $\dagger$ ), and the double-stranded ONT VI containing the trans-PtTz modified site were prepared following a similar procedure described above. The formation of double stranded ONT containing trans-PtTz binding site was confirmed by CD spectroscopy and FT-ICR-MS (Fig. S8d and f, $\mathrm{ESI} \dagger)$.

\section{Electrophoretic mobility shift assay}

Fluorescein-labeled single-stranded ONTs, designated as F-II and F-V, were obtained from Sangon Biotech (Shanghai, China). Fluorescein-labeled 1,2-cis-Pt-III and 1-trans-PtTz-VI were obtained by annealing 1,2-cisplatinated I with $1 \mathrm{~mol}$ equiv. F-II and the mono-functional platinated ONT IV with 1 mol equiv. F-V, respectively. For EMSA experiments, an aliquot $(1 \mu \mathrm{L})$ of the fluorescent labeled double-stranded 1,2-cis-Pt-III $(1 \mu \mathrm{M})$ or 1-trans-PtTz-VI $(1 \mu \mathrm{M})$ was mixed with various volumes of HMGB1a protein $(15 \mu \mathrm{M})$, and the binding buffer (20 mM HEPES, $50 \mathrm{mM} \mathrm{NaCl}, 5 \mathrm{mM} \mathrm{MgCl}_{2}$ and $10 \%$ (w/v) glycerol) was added to make a final volume of $10 \mu \mathrm{L}$. The mixtures were incubated at room temperature for $2 \mathrm{~h}$ prior to sampling. The protein-DNA complexes were separated in $6 \%$ non-denaturing polyacrylamide gels in $1 \times$ Tris-borate-EDTA buffer ( $\mathrm{pH} 8.1$ ) run at $50 \mathrm{~V}$ at $4{ }^{\circ} \mathrm{C}$ for $60 \mathrm{~min}$. After electrophoresis, the gels were excited at $488 \mathrm{~nm}$ wavelength and recorded at $600 \mathrm{~nm}$ by scanning with a Typhoon TRIO Variable Mode Imager (GE Health).

\section{Hydrogen/deuterium exchange protocol}

Firstly, HMGB1a $(232 \mu \mathrm{M})$ was incubated with 2 equiv. mol of 1,2-cis-Pt-III or 1-trans-PtTz-VI in buffer ( $\mathrm{pH} 7.4$ ) containing $20 \mathrm{mM}$ HEPES and $200 \mathrm{mM} \mathrm{NaCl}$ at $295 \mathrm{~K}$ for $32 \mathrm{~min}$ to form a respective HMBG1a-platinated DNA complex. For global deuterium uptake, $27 \mu \mathrm{L}$ of $\mathrm{D}_{2} \mathrm{O}$ was added to $3 \mu \mathrm{L}$ of HMGB1a alone or each HMGB1a-platinated DNA complex to initiate $\mathrm{H} / \mathrm{D}$ exchange. At various times, the HDX was quenched with $3 \mu \mathrm{L}$ ice-cold FA (20\%) containing different concentrations of protamine sulfate, which was used to remove excess of platinated DNA from the DNA-HMGB1a complexes prior to MS analysis, to give a final $\mathrm{pH}$ of 2.5 , and a $10: 1$ ratio $(\mathrm{m} / \mathrm{m})$ of protamine sulfate/DNA. The deuterated protein was loaded immediately onto a CAPCELL PAK $C_{8}$ column $(1.0 \times 35 \mathrm{~mm}, 300 \AA$, Shiseido). The column was washed with $1 \%$ solvent B (273 K)

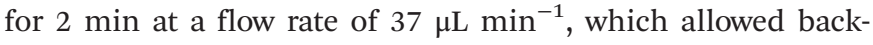
exchanging of the labile sites of the protein. Then, a gradient of $53-80 \%$ solvent B within 7.5 min was used to elute the protein directly into the mass spectrometer.

For local deuterium uptake, the HDX reaction of HMGB1a or HMGB1a-platinated DNA complexes was quenched by $20 \%$ FA mixed with isovolumetric pepsin $\left(2 \mu \mathrm{g} \mu \mathrm{L}^{-1}\right.$ in $\left.\mathrm{H}_{2} \mathrm{O}\right)$ at different times. The digestion was conducted at $273 \mathrm{~K}$ for $3 \mathrm{~min}$, then the peptic digests was loaded on a symmetry- $C_{18}$ column $(1.0 \times 50 \mathrm{~mm}, 100 \AA$, $3.5 \mu \mathrm{m}$, Waters $)$. The column was washed with $5 \%$ solvent $\mathrm{B}(273 \mathrm{~K})$ at $37 \mu \mathrm{L} \min ^{-1}$ for 2 minutes, back-exchanging the deuterium in labile sites of the peptides. The peptides were then separated with a LC gradient (10 to $35 \%$ B over $3 \mathrm{~min}, 35$ to $80 \% \mathrm{~B}$ over $0.5 \mathrm{~min}$ ) and infused directly to a mass spectrometer. The deuterium incorporation percentage of each peptide was determined from the centroid of the molecular ion isotope peaks using the 
HX-Express software. ${ }^{24}$ The deuterium percent was calculated by using the equation as follows:

$$
\text { Deuterium } \%=\frac{M_{\mathrm{HDX}}-M_{\text {control }}}{(N-2) \times 0.9} \times 100 \%
$$

where $m_{\mathrm{HDx}}$ is the centroid mass of the deuterated peptides, $m_{\text {control }}$ is the centroid mass of the nondeuterated peptides, $(N-2)$ is the number of exchangeable amide hydrogens, and 0.9 is the final $\mathrm{D}_{2} \mathrm{O}$ content of the buffer system.

\section{Electrospray ionization mass spectrometry coupled with liquid chromatography}

Positive-ion electrospray ionization mass spectrometry analysis was performed on a Micromass Q-TOF ultima global mass spectrometer (Waters) coupled to a Waters CapLC system. Mobile phases were A: $95 \% \mathrm{H}_{2} \mathrm{O}$ containing $4.9 \%$ acetonitrile and $0.1 \%$ formic acid (FA), and B: $95 \%$ acetonitrile containing $4.9 \% \mathrm{H}_{2} \mathrm{O}$ and $0.1 \%$ FA. The injector, loop, column and solvents were cooled to $2{ }^{\circ} \mathrm{C}$ to minimize back-exchange using a home-made low temperature box $(50 \times 50 \times 50 \mathrm{~cm})$ maintained at $2( \pm 0.2){ }^{\circ} \mathrm{C}$ by a refrigeration compressor. For mass spectrometry analysis, the desolvation temperature was $413 \mathrm{~K}$ and the source temperature was $353 \mathrm{~K}$. Nitrogen was used as both cone gas and desolvation gas with a flow rate of $40 \mathrm{~L} \mathrm{~h}^{-1}$ and $400 \mathrm{~L} \mathrm{~h}^{-1}$, respectively. The collision energy was set up to $10 \mathrm{eV}$. Global deuterium uptake spectra were acquired in the range of $\mathrm{m} / \mathrm{z} 500-2500$. Local deuterium uptake spectra were obtained in the range of $m / z$ 400-1800. MassLynx (ver. 4.0) software was used for analysis and post data processing.

\section{Docking simulation}

The crystal structure of HMGB1a ligated with a 1,2-GG intrastrand crosslink (1,2-cis-Pt-III) was obtained from the Protein Data Bank (code: $1 \mathrm{CKT})^{6}$ to reconstruct the $3 \mathrm{D}$ molecular models of the 1,2-cis-Pt-III-HMGB1a complex. The 3D molecular model of the monofunctional platinated double strand VI by trans-PtTz (1-trans-PtTz-VI) was constructed in Sybyl X1.1 (Tripos Inc.). The docking simulations between HMGB1a and each platinated DNA adduct were performed on Hex 8.0.0 software (http://www.loria.fr/ ritchied/hex/). ${ }^{25}$ The platinated DNA molecule (moving molecule) was systematically moved within the shape of the protein to match $\mathrm{H}$-bonding interactions and hydrophobic contacts between the receptor and the ligand, and electrostatic potentials were then calculated for the HMGB1a protein (stationary molecule). The docking correlation type was set as shape and electron, receptor range and ligand range were all set as $90^{\circ}$. The resulting molecular models were reconstructed by Sybyl X1.1 and/or Pymol ver1.1r153.

\section{Acknowledgements}

We thank the NSFC (Grant No. 21575145, 21135006, 21127901, 21275148, 21321003 and U1332210 (Y. L.)), the 973 Program of MOST (2013CB531805) for support, and Dr Tao Bing at the
Institute of Chemistry, Chinese Academy of Sciences for help and advices on EMSA experiments.

\section{Notes and references}

1 (a) C. A. Lepre and S. J. Lippard, Nucleic Acids Mol. Biol., 1990, 9-38; (b) A. E. Egger, C. G. Hartinger, H. Ben Hamidane, Y. O. Tsybin, B. K. Keppler and P. J. Dyson, Inorg. Chem., 2008, 47, 10626-10633.

2 (a) J. M. Pérez, M. A. Fuertes, C. Alonso and C. NavarroRanninger, Crit. Rev. Oncol./Hematol., 2000, 35, 109-120; (b) G. Natile and M. Coluccia, Trans-Platinum Compounds in Cancer Therapy: A Largely Unexplored Strategy for Identifying Novel Antitumor Platinum Drugs, in Metallopharmaceuticals, ed. M. J. Clarke and P. J. Sadler, Springer, Berlin, 1999, pp. 73-98; (c) N. Farrell, Current Status of Structure-Activity Relationships of Platinum Anticancer Drugs: Activation of the Trans Geometry, in Metal Ions in Biological Systems, ed. A. Sigel and H. Sigel, Marcel Dekker, New York, Basel, and Hong Kong, 1996, pp. 603-639.

3 (a) J. Kasparkova, O. Novakova, N. Farrell and V. Brabec, Biochemistry, 2003, 42, 792-800; (b) V. Marini, P. Christofis, O. Novakova, J. Kasparkova, N. Farrell and V. Brabec, Nucleic Acids Res., 2005, 33, 5819-5828.

4 M. E. Bianchi and A. Agresti, Curr. Opin. Genet. Dev., 2005, 15, 496-506.

5 (a) S. U. Dunham and S. J. Lippard, Biochemistry, 1997, 36, 11428-11436; (b) E. A. Pasheva, I. Ugrinova, N. C. Spassovska and I. G. Pashev, Int. J. Biochem. Cell Biol., 2002, 34, 87-92; (c) P. Pil and S. Lippard, Science, 1992, 256, 234-237.

6 U.-M. Ohndorf, M. A. Rould, Q. He, C. O. Pabo and S. J. Lippard, Nature, 1999, 399, 708-712.

7 S. M. Aris and N. P. Farrell, Eur. J. Inorg. Chem., 2009, 10, 1293-1302.

8 Z. F. Du, Q. Luo, L. P. Yang, T. Bing, X. C. Li, W. Guo, K. Wu, Y. Zhao, S. X. Xiong, D. H. Shangguan and F. Y. Wang, J. Am. Chem. Soc., 2014, 136, 2948-2951.

9 E. R. Jamieson and S. J. Lippard, Chem. Rev., 1999, 99, 2467-2498.

10 (a) Z. P. Yao, M. Zhou, S. E. Kelly, M. A. Seeliger, C. V. Robinson and L. S. Itzhaki, J. Mol. Biol., 2006, 363, 673-686; (b) J. Zheng, H. Y. Yong, N. Panutdaporn, C. Liu, K. Tang and D. Luo, Nucleic Acids Res., 2015, 43, 12161230; (c) R. Beveridge, L. G. Migas, K. A. P. Payne, N. S. Scrutton, D. Leys and P. E. Barran, Nat. Commun., 2016, 7, 12163; (d) K. A. Donovan, S. L. Zhu, P. Liuni, F. Peng, S. A. Kessans, D. J. Wilson and R. C. J. Dobson, J. Biol. Chem., 2016, 291, 9244-9256; (e) C. Lento, D. J. Wilson and G. F. Audette, Struct. Dyn., 2016, 3, 012001; (f) T. Raschle, P. R. Flores, C. Opitz, D. J. Muller and S. Hiller, Angew. Chem., Int. Ed., 2016, 55, 5952-5955.

11 L. Y. Pan, O. Salas-Solano and J. F. Valliere-Douglass, Anal. Chem., 2015, 87, 5669-5676. 
12 W. Hu, J. Liu, Q. Luo, Y. Han, K. Wu, S. Lv, S. Xiong and F. Wang, Rapid Commun. Mass Spectrom., 2011, 25, 14291436.

13 J. O. Thomas and A. A. Travers, Trends Biochem. Sci., 2001, 26, 167-174.

14 M. Bustin and R. Reeves, Prog. Nucleic Acid Res. Mol. Biol., 1996, 54, 35-100.

15 (a) Q. He, U. M. Ohndorf and S. J. Lippard, Biochemistry, 2000, 39, 14426-14435; (b) E. R. Jamieson and S. J. Lippard, Biochemistry, 2000, 39, 8426-8438.

16 L. Tang, E. D. Hopper, Y. Tong, J. D. Sadowsky, K. J. Peterson, S. H. Gellman and M. C. Fitzgerald, Anal. Chem., 2007, 79, 5869-5877.

17 A. Poliakov, P. Jardine and P. E. Prevelige, Rapid Commun. Mass Spectrom., 2008, 22, 2423-2428.
18 J. B. Sperry, J. M. Wilcox and M. L. Gross, J. Am. Soc. Mass Spectrom., 2008, 19, 887-890.

19 http://web.expasy.org/protparam/.

20 http://web.expasy.org/findpept/.

21 S. F. Bellon and S. J. Lippard, Biophys. Chem., 1990, 35, 179-188.

22 M. Van Beusichem and N. Farrell, Inorg. Chem., 1992, 31, 634-639.

23 J. A. Parkinson, Y. Chen, P. D. Murdoch, Z. J. Guo, S. J. Berners-Price, T. Brown and P. J. Sadler, Chem. - Eur. J., 2000, 6, 3636-3644.

24 D. Weis, J. Engen and I. Kass, J. Am. Soc. Mass Spectrom., 2006, 17, 1700-1703.

25 (a) D. W. Ritchie and G. J. L. Kemp, Proteins: Struct., Funct., Genet., 2000, 39, 178-194; (b) D. W. Ritchie, Curr. Protein Pept. Sci., 2008, 9, 1-15. 